\title{
CONSTRAINING FACTORS TO THE ADOPTION OF KISWAHILI AS A LANGUAGE OF THE LAW IN TANZANIA
}

\author{
B RWEZAURA*
}

\section{Introduction}

The political and economic problems of language policy in modern Africa have continued to remind us of the unforgettable historical fact of European colonialism. Today there are two major regions of Africa known as Anglo-phone and Franco-phone Africa Much as many African leaders would have wished to discard the language of the former colonial power and substitute an indigenous language, this was problematic because in many cases there was not a single widely-spoken local language In some cases any attempt to raise the status of one indigenous language into a national language might have provoked wasteful inter-ethnic conflict

The political considerations emanating from ethnic diversity is another legacy of colonialism The arbitrary drawing of colonial boundaries during the late 19th century not only dissected ancient kingdoms and nationalities but also grouped together peoples of differing cultures and languages Tanzania, a former British trust territory, stands out as one of the few exceptions to this general rule. This is because Kiswahili is widely spoken in the country Given this initial advantage, it would be instructive for this reason alone to see how Kiswahili was developed as a national language. This article argues, however, that Tanzania did not fully exploit this language potential to make Kiswahili a medium of communication in all aspects of national life To do this the paper takes one aspect of language use, the problems faced in the development of an indigenous national language in one African state. It is hoped that the experience of Tanzania might offer some insights to other African countries which are engaged in similar concerns

The article is divided into seven sections including this introduction. The second contains a brief overview concerning the use of Kiswahili in Tanzania and the importance of adopting a single language in such a community. The third section examines the post-colonial drive to make Kiswahili a truly national language in lieu of English and also considers the consequences and limits of this campaign In the fourth section, the article looks at the extent to which Kiswahili is used in the legal system and considers the contradictory developments regarding the use of Kiswahili as the language of the law. On the one hand there is the willingness of the courts (including even superior courts) to use Kiswahili during trials, whilst on the other is the continued reluctance to adopt it as a medium of legal education at university level By looking at the lack of institutional coordination between the Ministries of Education and Justice as trainers and employers of law graduates, this article will try to account for these contradictory developments. The fifth section looks at the various factors which constrain the adoption of Kiswahili as the language of law and the sixth section, the article tries to make a case for its 
adoption, stressing especially the fact that the Kiswahili language has become so widely used in the legal system that the government can no longer ignore it. It is argued therefore, finally, that perhaps the time has come for the government to commit adequate resources to build Kiswahili systematically and adequately as a second language of the law, at least in the interim period, until a further decision is made to adopt it as the sole language of the law

\section{The Use of Kiswahili in Tanzania}

The United Republic of Tanzania acquired its present name in 1964, following a union of two sovereign states; Tanganyika and Zanzibar Previously both states had been under British colonial administration. Tanganyika became independent in 1961 to be followed by Zanzibar two years later. It has a population of about 24 million (1988 Census) distributed unevenly across several ecological zones with the highest density of about 260 people per sq. kilometre Most of the population (about $87 \%$ ) are engaged in small holder peasant agriculture and animal husbandry and are therefore concentrated in the fertile highland and lake regions of the country where the rainfall is reliable and the soils richer

Like its Eastern African neighbours, Tanzania has a multi-racial as well as multi-ethnic population. The major racial groups include Africans (who constitute the majority), Asians (originally from Arabia and the Indian sub-continent) and Caucasians (mainly British and other Europeans) There are also people of mixed parentage especially from Zanzibar and the coast who have resulted from the inter-marriages of Africans and Arabs The ethnic composition of the country is even more diverse. There are at least 120 ethnic groups of which the largest has a population of about 35 million. Each of these communities, or groups within them, have their own vernacular language or dialect which is distinct from Kiswahili. Kiswahili is a Bantu language which has borrowed substantial vocabulary from Arabic and more recently from English (Whiteley 1969; Massamba 1985)

Kiswahili is believed to have originated from a Bantu ethnic group residing somewhere on the East coast of Africa and later to have been popularised by the slave traders who spread it to other trading posts in the hinterland as well as Zanzibar (Massamba 1985). During the postslave trade period Kiswahili became a mother tongue to some of the descendants of the freed slaves as well as to some coastal peoples who were the offspring of inter-marriage of Arabs and Africans. During the German and British colonial periods, Kiswahili was again popularised because it was seen as a practical means of communication and colonial administration of the region. Christian missionaries also used Kiswahili and other local languages to spread the gospel as well as in formal education (Wright :1965). Thus although only about $10 \%$ of the population today speak Kiswahili as their mother tongue, it is estimated that about $90 \%$ of the population have a working knowledge of and speak the language (O'Barr 1976).

For most Tanzanians, therefore, Kiswahili is not a mother tongue A child in a rural village comes formally into contact with Kiswahili at the age of six when he/she begins to attend preschool classes. Urban based children come into contact with Kiswahili at an earlier age because the language is widely spoken in urban areas and there is also much social interaction between members of different ethnic groups. In the case of adults, their constant contact with people 
from other ethnic groups, even at village level, suggests that they need Kiswahili in order to operate effectively. Government and Party officials and people engaged in commerce use Kiswahili. Hence, whatever imperfect Kiswahili a primary school graduate may have picked up at school, this may improve with the degree of external contact he/she may establish over time Thus, according to O'Barr (1976), men tend to have better knowledge of Kiswahili than women because of their external contact. Younger people are overall better versed in the language because they have greater opportunity of using Kiswahili For most rural folk, however, (and even urbanites) Kiswahili is not spoken in the home unless there is a compelling reason such as the presence of a family member or a guest who does not speak the vernacular language Hence, as noted by Abdulaziz-Mkilifi, (1972) even among fluent speakers of Kiswahili, vernacular is still spoken in intimate communication between friends and relatives.

During the 1950s when former President Julius Nyerere began his campaign for political independence, Kiswahili emerged as the unifying language and became an important tool for mass mobilization throughout the entire country The radio, local newspapers and political rallies were all conducted in Kiswahili It cannot be doubted therefore, that by independence in 1961 , Kiswahili had attained a high degree of political prestige as well as wide acceptability in the whole country Even more significantly, Kiswahili was not clearly associated with a particular ethnic group and hence its use did not provoke any of the political problems associated with ethnic domination. During the same period, the drive of nationalistic politics added impetus to the popularity of Kiswahili This was the time when politicians preached about cultural autonomy, national identity and the rejection of symbols of colonial domination including the use of English language in public administration. Indeed as correctly noted by Massamba (1985: 6) Kiswahili was, during the independence struggles, "associated with nationalism, patriotism, and liberation". It is in this political atmosphere that we must locate the decision to make Kiswahili the national language and eventually the language of the law in Tanzania

\section{Building Kiswahili into a National Language}

Soon after independence the then Prime Minister, Rashid Kawawa, declared that Kiswahili would become a national language to be used at state and public functions. Kiswahili was also to be a second language in Parliament along with English (Massamba 1985:14; TrappesLomax 1990:98). During this period, the government convened a committee of experts to advise on the policy of adopting Kiswahili as a national language, bearing in mind the challenges facing a rapidly developing African country. The committee included some lawyers, Kiswahili experts and administrators (Weston 1965). Among the recommendations of this committee was the setting up of a language corporation which would be assigned the task of formulating as well as implementing the policy decisions on Kiswahili One of its departments, it was recommended, would undertake the compilation of specialised vocabulary for use in public administration, higher education and the law Although the language corporation was not established, some of its envisaged functions were assigned to various public institutions These included the National Swahili Council (Bakita), established in 1967 and assigned the 
functions of promoting, coordinating and overseeing the development of the language The Ministry of Education, undertook to develop Kiswahili vocabulary for use in educational institutions

The task of formulating legal vocabulary was taken up in 1963 by the then Minister of Justice, Sheikh Amri Abedi, who convened a law dictionary committee consisting of lawyers and Kiswahili language experts Within two years of its formation, the committee was able to produce a compilation of Kiswahili terms and phrases. The work of this committee has been ably described by one of its original members who was then the Dean of Law at the University of East Africa (later to become the University of Dar es Salaam). Although the dictionary committee ceased to be active soon after the publication of the law dictionary, many of its members continued their work as members of the National Swahili Council (Bakita) The Ministry of Education in co-operation with the Institute of Kiswahili Research at the University of Dar es Salaam continued to work on the creation and expansion of technical vocabulary for use in schools and public administration.

There are indeed many new words which resulted from this effort They included titles of senior government officers which sounded rather awkward at the beginning mainly because they did not carry the usual (or colonial?) aura of office, but after regular usage were soon accepted. Indeed even the military parade commanders who believed that commands issued in the English language were more authoritative than those made in Kiswahili had to use the national language The Institute of Kiswahili Research at the University of Dar es Salaam did most of the work of developing appropriate vocabulary it also produced an up-to-date monolingual Kiswahili dictionary in which all the new vocabulary was included (Tumbo 1982)

While all these efforts were under way, the government made a number of specific decisions concerning the use of Kiswahili. All civil servants were instructed, by an official directive of 4th July 1967, to use Kiswahili in the discharge of their duties especially in correspondence and oral communication Debates in Parliament were to be conducted in Kiswahili and to be reported in that language. The Government Gazette as well as subsidiary legislation was also to be in Kiswahili It was envisaged that principal legislation would also be drafted and published in Kiswahili For the time being, a Kiswahili version of "Objects and reasons" would be appended to all statutes which, meanwhile, would continue to be published in English

In the courts of law two languages would continue to be used with Kiswahili in Primary courts (the lowest level) and English in the District and Resident Magistrates' Courts and the High Court Translators who worked mostly as court interpreters and clerks would be available to translate from local languages into Kiswahili in the lower courts and between English and Kiswahili in the higher courts. During this early period, basic statutes used in the lower courts were translated into Kiswahili. They included the Primary Courts Civil Procedure Rules (Govt. Notice No 22 of 1964); the Primary Courts Criminal Procedure (as 3rd Schedule to Magistrates Court Act; Cap 537 of 1963) and the Primary Courts Evidence Rules (Govt Notice No 22 of 1964). Later, in 1971, a Kiswahili version of the Law of Marriage Act, (No 5 of 1971) was added. It was envisaged that more statutes would be translated over time to enable the lower courts to work more efficiently. As we shall see later this objective was not 
attained The possibility of producing a Kiswahili version of the Law Reports of Tanzania was also considered by the editorial committee but this idea was not implemented due to lack of resources

There remained the question of teaching law in Kiswahili at the Faculty of Law, which until 1971, was part of the University of East Africa. The composition of law undergraduates included, at this time, students from Kenya and Uganda where Kiswahili, though widely spoken, was not used to the same scale as Tanzania and was not considered a possible future language of the law Furthermore, many of the law teachers were expatriates with no working knowledge of Kiswahili Even then, a committee had been established at the Law Faculty, headed by a native Kiswahili speaking lecturer, to advise and promote the use of Kiswahili in the teaching of law and to encourage local lecturers to write law books in that language Although the committee was not as active as the Law Dictionary committee, its presence in the Faculty of Law encouraged the writing of law books in Kiswahili There were comparable efforts by other lawyers, who published a series of pamphlets on various law topics. Law students, working under the Faculty of Law Legal Aid Committee, gave legal advice to members of the public in Kiswahili and also mounted a successful radio programme for the wider public. The material from some of these programmes was later published in book form Kiswahili newspapers also carried columns about law entitled; "Sheria na Wewe" ("the law and you") In Zanzibar, similar measures were taken soon after the 1964 revolution when Kiswahili was declared to be the official language and all people including civil servants were strongly advised to use the language (Massamba 1985:15) Besides the efforts of lawyers to promote Kiswahili, a number of significant changes were effected in the education system A department of Kiswahili was established in 1970 at the University of Dar es Salaam to train Kiswahili teachers for secondary schools and colleges of education. Kiswahili became a medium of instruction in a new subject called Siasa (political education) which was introduced at both Ordinary and Advanced Levels of secondary school curriculum. Siasa replaced General Paper at $\mathrm{A}^{\prime}$ Level and was given the same rating as that originally given to English in the Cambridge School Certificate examination. Furthermore, Kiswahili was given academic prominence by requiring candidates to pass it before they could be awarded a higher classification.

In sum, the enthusiasm for the adoption of Kiswahili as the national language was very considerable during the first two decades after independence It was also much used in adult education and general mass mobilisation for development In the next part of this paper I examine briefly what has been achieved in the promotion of Kiswahili as the language of the law, the problems which have been encountered and the possible future solutions

\subsection{The Use Kiswahili as the Language of Law Today}

The term "language of the law" as used in this paper refers specifically to the language in which the legal system functions. This includes, first, the legislature, that is the language in which bills and subsidiary legislation are drafted, debated and finally passed; and secondly, the judiciary, that is the language in which court process and proceedings are conducted, including 
oral and written submissions, evidence and the final decree of the court. Whilst limiting the scope of the term in this manner, it is not intended to define law narrowly to ignore the fact that there are other important spheres where law and language play a vital role. Indeed the language used in this wider field has significant consequences for the first category. A good example is the language of legal education which invariably affects the way lawyers and judges will do their jobs. But there are also other areas of equal importance such as police duties, and lawyer and client interviews which are, in the majority of cases, conducted in Kiswahili. The language used on such occasions should also be seen in general terms to be the language of the law Except for the language of legal education, the use of Kiswahili in these other contexts is not considered in this article. Nevertheless, when it is argued finally that the greater part of the business of the legal system in Tanzania is now conducted in Kiswahili, one has to bear in mind these aspects as well.

\subsection{The Use of Kiswanili in the Courts}

With effect from 1985 it can be confidently stated that the law permits all courts in Tanzania to use Kiswahili, to a certain extent, provided the presiding judge so directs As noted above, the primary courts are required to use Kiswahili in the entire proceedings, thai is both oral and written (sec 13(1) MCA) It is significant to note here that the magistrates who preside over these courts are not professional lawyers. Moreover, no attorneys are permitted to represent clients at this level. The proceedings are usually much less formal than the courts above But the significance of Primary Courts lies in their accessibility to wider society. Indeed primary courts process the greatest volume of all judicial work in the country.

The District courts are also presided over by persons who have some training and experience in law but are not qualified lawyers Many of them are former Primary Court magistrates who have distinguished themselves on the bench These courts can and do conduct their proceedings in Kiswahili but the Magistrate must write the court record as well as the judgement in English. Advocates are permitted to appear at this level of court and are required to make their written submission and correspondence with the court in the English language At the Resident Magistrates' Courts which are presided over by professional lawyers, and where also advocates can appear, Kiswahili is optional but tends to be used more than English in oral proceedings (Kavugha \& Bobb 1980) But here again, the court record has to be written in English. As noted above, interpreters are available whenever needed and are used when a non-Kiswahili-speaking attorney appears for any of the parties There is no political or other pressure on the Magistrate to use either language but from a practical point of view it makes sense to use Kiswahili

There are encouraging developments to be noted regarding the use of Kiswahili at the High Court level Although judges still write all the proceedings in English including the judgements, and all written submissions to the court are required to be in English, they permit attorneys to examine witnesses in Kiswahili. Counsel still make their oral submissions in English but may also use Kiswahili if the judge permits. This new development has been possible after the 
amendment in 1985 of the Tanzania Court of Appeal Rules 1979 which now permit Judges of the High Court and Court of Appeal to use Kiswahili

Equally significant have been the developments in the language used in quasi-judicial tribunals some of which are presided over by High Court judges or judicial officers of comparable rank. They include the Industrial Court of Ianzania and the Permanent Commission of Enquiry which now conduct their hearings both English and Kiswahili

A study done in 1970 by Kavugha and Bobb (1980) concerning the frequency of Kiswahili use in the Tanzania courts confirms the above observations It shows that Kiswahili, relative to English, was used in 28 per cent of the time at the High Court, 56 per cent of the time at the Resident Magistrates' Court, 79 per cent of the time at the District Court and 92 per cent of the time at the Primary court levels The use of vernacular was insignificant in all courts This study also noted a regular language switch from English to Kiswahili as circumstances demanded

It seems that this willingness to use Kiswahili in the superior courts is a consequence of many factors. The most important of these include the total indigenisation of the Judiciary, the Attomey General's chambers, the Ianzania Legal Corporation and the Bar. These are the principal institutions of the legal system. The heavy workload of the courts, the importance of expediting trials and the usually less than adequate ability of the court interpreters, make it all the more necessary to use a language which is mutually comprehensible even if it does not fully express with finesse the legal concepts of the English common law on which the Tanzania legal system is based Many judges recognise that it is no longer excusable for a Tanzanian judicial officer to sit back waiting for an English translation to be made of a testimony given in Kiswahili which he or she understands and can more effectively translate on paper than the often inarticulate court clerk Court clerks are not trained interpreters and their formal education is normally at ordinary level secondary school This indicates that their ability to work in English is very limited indeed

\subsection{The Use of Kiswahili in Parliament}

Perhaps because of the diverse composition (in terms of educational backgrounds) of the Tanzanian National Assembly and its more obvious political functions, since 1965/66 Kiswahili has been used in debates and the proceedings of the House have been published in the national language Bills however continue to be drafted in English with the single exception of the state Constitution (1977) and that of Zanzibar which were drafted and presented in Kiswahili All subsidiary legislation is drafted in Kiswahili as well as the Government Gazette

It seems that the consequences of not adopting Kiswahili completely as the language of the law are manifested at this level much more clearly. This is because when a bill is drafted in English and then presented in the Parliament and debated in Kiswahili, it is difficult to say that all Members of Parliament do understand its essential elements the more so when proficiency in English is not a precondition for election to Parliament There are indeed many MPs, especially those from Zanzibar, who cannot speak a word of English It is unrealistic to expect 
Members of Parliament to debate Bills which are published in a language they cannot read There is here, therefore, a very strong case for demanding that all bills be published in both Kiswahili and English

With the political changes going on in Tanzania now, especially, the reassertion of the political prestige of Parliament as supreme law making organ of the state, which hopefully is to be constitutionally guaranteed, it will be quite difficult to maintain this position. Hence, if the future Parliament of Tanzania were to pass a law making it a requirement that all bills be in both English and Kiswahili, it would be a short step before the legal system became truly bilingual Should the position be reached whereby both languages have equal weight and can be used in Parliament and courts, and the court records can be in either language, it would be another short step to the adoption of Kiswahili as the ultimate language of the law in Tanzania.

\subsection{Constraining Factors to the Total Adoption of Kiswahili}

As noted above, Kiswahili is not the sole language of the law as English is still the more dominant official language in the superior courts and the language in which court records are kept and judgements written. This is reflected also by the fact, noted above, that bills are still drafted and presented to the legislature in English It would appear therefore, that the use of Kiswahili in the superior courts, even though permitted by law, is a matter of expedience rather than a deliberate policy decision Judges and counsel resort to Kiswahili spontaneously and, as noted by Kavugha \& Bobb, sometimes switch between the two languages. This lack of policy on the role of Kiswahili in the legal system of Tanzania is more clearly demonstrated by the absence of the essential elements of a bilingual legal system These include the availability of authoritative versions of legislation in both languages and the right to prepare court records in both languages and to use any one of the two in court

There are at least three factors which appear to have contributed significantly to the failure to adopt Kiswahili completely as the language of the law in Tanzania These are first, that the language of legal education as well as the supporting educational resources continues to be in English; secondly, that legal education is affected by a wider national policy on language as a medium of instruction; and thirdly, that the government has failed to allocate sufficient resources and to encourage the building of Kiswahili into the language of the law

Although these three factors are in many ways interlinked, they will be considered separately below in order to stress their relative contribution to the present situation

\subsection{The Language of Legal Education}

Since the Faculty of Law was established in 1961, English has been used as the medium of instruction Although much optimism was expressed by, A B Weston, the founding Dean, that once the Faculty of Law had become fully localised, law students would be taught in Kiswahili and trained to make submissions and legal arguments in that language, this has not happened at all The only part of Weston's prediction which has come true is that total localisation of the 
Faculty was achieved nearly two decades ago Apart from the activities mentioned already, concerning the work of the Legal Aid Committee, the publication of the law dictionary (out of print since the mid-1970s) and a few Kiswahili books, nothing more has been done. There has been no visible academic debate nor that I am aware of, or any writing on the subject of teaching law in Kiswahili. It is indeed true, as noted by Chen, (1989:212) that the problems of law and language in former British colonies have been a neglected subject of legal discourse

Many reasons can be given to account for this lack of interest They include the fact that law teachers have to be very committed and keenly innovative to try to teach law in a language in which they did not themselves study the subject. Perhaps that is why the Kiswahili Committee to which reference was earlier made, never received much support from law teachers. But it was not actively opposed either. In its report to the Board of the Faculty of Law, the committee expressed great reservations as to the feasibility of using Kiswahili as a medium of instruction. After detailing the various problems that would have to be confronted, the committee concluded that the task was not only enormous but there would be no resources to support the undertaking

Another reason is the feeling among the law teachers that teaching law in Kiswahili would deprive students a proper understanding of basic English common law principles on which the Tanzania legal system is grounded. And this, it might be argued, would have the effect not only of transforming the jurisprudence of the country but also of isolating the country s legal profession from the common law world. As noted already, these issues were never openly raised and no one therefore expressed views on them. However, the experience of other former British colonies such as Sti Lanka (Zafrullah 1992), Malaysia (Mahmood 1992), and Bangladesh (Alam 1992), indicates that the subject is much debated elsewhere Yet, from my own experience at the Dar es Salaam Law Faculty (1972-1990), I can say that during the last ten years there has been a growing interest among the students in the possible use of Kiswahili in legal education. If encouraged, students have become more willing than before to discuss their assignments in Kiswahili Indeed some students, after the customary greeting in Kiswahili, would proceed to introduce their subject in the same language At this point some teachers, would politely remind them that the official language of legal education was English. This insistence on the use of English would earn the teacher a nick-name of mzungu (white man) or even worse mkoloni (colonial-minded). Though of course there were other students who were highly impressed by some teachers' good command of the English language and would take them as their role model.

Whether or not this tendency to speak to the Tanzanian teachers in Kiswahili is a consequence of the falling command of the English language among even the best students, or of culturally inspired attraction for the language (such as using Kiswahili out of respect and politeness), the conclusion which can be drawn is that the English language has become progressively marginalised. Today, even at the University of Dar es Salaam, English is merely the language of the lecture room This fact has been noted by others such as Trappes-Lomax who has noted that a visitor to the University of Dar es Salaam in 1988 will not hear English spoken between Tanzanians "unless he happened to overhear a lecture or a seminar or a departmental, faculty or senate meeting" (1990:98) 
But this situation has not come about overnight. According to Trappes-Lomax the period of the mid-1960s to the mid-1980s, has witnessed the shift in status of English in Tanzania from a second towards a foreign language The same period has witnessed a decline in the standards of English in the educational system Thus a combination of factors appear to have led to the marginalisation of English. The decline in the standard of English in schools necessarily affects any debate on whether or not English should be retained as the main language of the law in Tanzania

\subsection{The Effect of National Language Policy on Education.}

As already noted above, the failure to use or even seriously consider Kiswahili as a medium of legal education is not to be seen in isolation. The Faculty of Law is part of the University of Dar es Salaam which is under the Ministry of Education (now Ministry of Higher Education). It is affected by all the decisions of the government regarding policy as well as budgetary allocation It is helpful, therefore, to take a brief look at the measures taken by the Government to adopt Kiswahili as a medium of instruction in institutions of learning.

When in 1967 Kiswahili was made a medium of instruction in all primary schools, it was envisioned that in 1973 the same requirement would be extended to the first two years of secondary education (Rubagumya 1986:284). This was not done. In 1982 a Presidential Commission on Education (the Makweta Commission) recommended that with effect from January 1985 Kiswahili would be used for purposes of instruction in all secondary schools and that by the year 1992, the same would be extended to University level (Batibo 1982). Not only were these recommendations put on hold but the Government kept silent for several years This lack a definite decision on the matter created much ambivalence and speculation as to Government intentions

Although the absence of a clear language policy may have indirectly benefited the English language by slowing down its further decline, the period of the 1970 s reveals a continuing fall in the English language competence among the majority of secondary school graduates. These weaknesses were revealed at University level and other tertiary level institutions. Lecturers at the University of Dar es salaam and the Medical School noticed that many of the newly admitted undergraduates were not able to express themselves clearly or to write competently in English. The language problem was worse in faculties of social sciences and law where students were expected to read substantial amounts of literature and to write long essays External examiners also noted that the problem of language competence needed urgent attention as it was getting worse each passing year. Research conducted on the teaching of English as a second language in primary and secondary schools revealed grave deficiencies (Matteru \& Mlama 1978; Mvungi 1974; Batibo 1990; Rubagumya 1986 \& 1990) It was suggested then that English language courses be introduced at specified levels and more emphasis be put on language skills. In response to this situation, in 1978 the University of Dar es Salaam established a Communications Skills Unit (CSU) to assist undergraduates by offering remedial courses (Rugemalira 1990:105-122). In addition, the Ministry Education 
obtained assistance from the British government for the rehabilitation of teaching of English in schools

Perhaps because of the rehabilitation project or in its anticipation, the Government announced in 1986 that the English language would continue to be a medium of instruction at secondary school level and above for a long time to come. Although the decision to maintain English as a medium of instruction has been rightly criticised by a number of researchers, it should not be expected that it will be reversed soon. It is not within the scope of this article to discuss the merits of this language policy, especially when it has been adequately shown that English is no longer a medium of but a barrier to instruction in most Tanzania secondary schools. What should be stressed is that one of the consequences of the present policy on language is that Kiswahili has not been fully adopted as the language of the law in Tanzania But also it should be added that perhaps because of the falling proficiency in the English language among recent graduates at University and lower levels, Kiswahili has become a language to which lawyers and others engaged in law-related work have resorted in order to overcome communication problems

In sum, while the judiciary and legal practitioners seem to have made much progress in the use of Kiswahili, perhaps largely because of the problems of communication already considered, legal education has continued to be imparted in English without responding adequately to the emerging challenges in legal practice throughout Tanzania It appears that lack of resources and initiative are among the main reasons why Kiswahili has not been adopted as the language of legal education

\subsection{The Problem of Resource Allocation}

Although the Tanzanian economy, like most other third world economies, is experiencing serious problems, there are certain sectors in the country which have suffered more in budgetary cuts than others. The Ministry of Justice has not been given priority in many areas of its operation and the office of the Parliamentary draftsman has insufficient numbers of competent translators who are able to translate statutes used frequently in the lower courts This accounts for the fact that bills are still presented to the National Assembly in English when, as noted before, a number of Parliamentarians are not versed in the English language

A look at the statutes published in Kiswahili shows a very modest record indeed The only major piece is the state Constitution (1977) which was published in Kiswahili and this forms the authoritative version The other pieces include the Law of Marriage Act (1971) and the Penal Code (Cap .16) the latter two were translated from English. But even these have not in many instances sufficiently captured the basic legal concepts behind the words. Although it is recognised that legal translation is a difficult task in its own right (Dickson 1991), and entails more than merely having competent staff, yet the significance of retaining an adequate number of translators in a legal system such as that of Tanzania can not be ignored

Thus where translation from English to Kiswahili is not done by a competent translator, there is the danger of losing the essential concepts which are expressed in certain terms and 
phrases. This may lead to much litigation and an endless exercise in interpretation It is not expected that Tanzanian translators will be instantly perfect when they begin their duties but certainly one does not see many of them and those few are perhaps too busy to engage in major statutory translations In addition, the government has not made any efforts to commission the writing of law books in Kiswahili or any translations of law books from English My own experience may be indicative. My first law book in Kiswahili was published by the Institute of Kiswahili Research as a measure to encourage the writing of law books in Kiswahili. The second was submitted to the Tanzania Publishing House in 1982 . It remained unpublished till 1992 due to budgetary problems The third book in the series which I had planned to write has remained uncompleted because of my uncertainty about its publication

To complete the argument concerning the problem of resource allocation, I need only add that the Judicial System Reform Commission (Msekwa Commission) which was appointed to study the problems of the legal system and make recommendations to the government, was not given as one of its terms of reference the problems of Kiswahili as the language of the law This also would appear to confirm the view that policy makers are not keen to commit any resources to the promotion of Kiswahili even as the second language of the law

\subsection{Why Kiswahili should be the Language of the Law}

The most obvious argument for adopting Kiswahili as the language of the law in Tanzania is that it has, in practice, become one For example, in one study it was found that Kiswahili was used in 78 per cent of the total court time compared with English (16 per cent) and vernaculars (6 per cent ) Kavugha \& Bobb (1980:233,237). This study was completed in 1970, even though it was published much later In view of the more recent studies cited in this article regarding the steady drop in English language proficiency in all schools and higher educational institutions, it is safe to speculate that more Kiswahili is now spoken in the courts than it was 20 years ago It is not likely that this trend will be reversed. As noted by Martin-Jones, English is, in the coming years, "likely to give way to Kiswahili as the latter becomes more developed and therefore more able to cope with the modern world" (1990:13)

But there are other reasons why Kiswahili should be encouraged to become the language of the law in Tanzania. These may be grouped into the following general categories: efficiency, legitimacy, due process of law, and national identity. These points will be briefly considered below

\subsection{Efficiency}

In order for the for the legal system to operate effectively it must not be hampered by factors such as lack of qualified personnel, and necessary resources such as up to-date statutes and books as well as other infrastructural support which are essential for the legal system to work Where, as in Tanzania, over 90 per cent of the population speak Kiswahili and less than 10 per cent are fluent in English, insistence on the use of English at any level will create the need for bilingual and translation services. Such service has its costs in terms of human resources, 
money and time. Where those providing the bilingual services are incompetent or inefficient, this will generate dissatisfactions among the people and may also lead to delay in the administration of justice or legislative process

Delay in the administration of justice is as much a problem in Tanzania as in other developing countriesand it cannot be denied that the use of a mutually understandable language will certainly facilitate speed in the judicial process This is one of the reasons why the superior court judges have now begun to allow the use of Kiswahili in oral proceedings. Yet, as noted before, judges and senior magistrates are not excused from having to write up the proceedings in English, a procedure which requires more time and mental exertion

\subsection{Legitimacy}

The term legitimacy is used here to convey the idea of relative acceptance of the legal system by the majority of the population Just as the efficiency of the legal system in any country is a result of many factors, so is the question of legitimacy My concern here is not the source or content of the law or the basic philosophy underlying it but the fact that for the laws of the country to be known and to a limited degree respected and obeyed, they have to be in a language which the majority of the people understand. The principle of law which every first year law student is taught that "ignorance of the law is no defence unless knowledge is a necessary ingredient of the offence" should be seen as a bad joke by the ordinary man in the street Chen has argued that where a legal system operates in a foreign language, this fact, inter alia, "intensifies the professional and elitist character of the legal system and ignores the democratic ideal of popular understanding of, and participation in, the legal system" (Chen 1989:217)

Many legal systems of former colonial African states have tried to face the problems of lack of legitimacy by indigenisation of the judiciary, the use of juries and in some cases by making limited institutional reform to tone down their colonial background. Even then many problems remain For example, the higher levels of the legal system are still inaccessible to the majority of the people due to the complexity of legal procedures, the physical and cultural distance of the court, the cost of hiring legal representation, and more generally, the inability of an ordinary man to mobilise the legal system to effect certain goals. To this list one must add the problem of language which makes it difficult for people to use the legal system effectively if at all.

\subsection{Due Process of Law}

The term "due process of law" is also used in a general and non- technical sense Whether in criminal or civil proceedings, the right of the main parties to know the language of the court is most basic This knowledge enables the parties to have a first hand knowledge of what is being said against them or on their behalf It is not contended that knowledge of the language completely demystifies the law; for indeed, even persons whose mother tongue is English cannot understand the technical aspects of the law Yet it at least enables them to follow the 
less technical aspects of the trial People have a right to know the charge against them, to be able to follow the proceedings and to prepare a competent defence if they are not legally represented

Hence, whereas one may be rightly concerned about the legitimacy of the legal system, it is important to remember that section 211 of the Criminal Procedure Act 1985 as well as the Bill of Rights can be invoked by a litigant or accused person to insist that the proceedings be the language which is known to him or her and may be able to insist on the right to the service of a competent court interpreter. It remains to be seen how the relevant provisions of the Bill of Rights can be used to effect changes in the language of the law in Tanzania

\subsection{National Identity}

The period following independence saw much political agitation for nation-building and cultural nationalism at all levels. This is the atmosphere in which the Kiswahili language grew With this political mood and trend in the country, what reasons can be given for the insistence that English should remain a language of instruction in all post-primary level schools for the foreseeable future as well as the language of the law?

The answer to this question is very complex The reason given by the government in 1986 for maintaining English as a language of instruction in all tertiary level educational institutions was that the English language played a significant role in enabling Tanzanians to gain access to Western education. English was also seen as essential if Tanzania is to avoid isolation from the English-speaking world As the Julius Nyerere once put it, whereas Kiswahili is essential for all Tanzanians to communicate with each other, English is a world language and Tanzanians need it to speak to the world Yet underlying this is the fact that western form of education is still considered in many parts of Africa, and perhaps elsewhere, to be a key to gaining access economic power and social status. The bureaucrats in government who formulate the language policy reflect the views of most parents many of whom still believe rightly or otherwise that Kiswahili is not sufficiently empowering

There is also a growing private sector education in Tanzania in which many parents are now investing money and are able to participate directly in policy-making. Here again Kiswahili has not been preferred to English as the medium of instruction because some parents think this would limit their children's chances for better education abroad. It is also officially claimed that to adopt Kiswahili as the sole medium of instruction would isolate the country and deprive it all the benefits of scientific and technological advancement. While this may be true to a limited extent it cannot justify a position where less than 5 per cent of all primary school leavers do not make it to state secondary schools and the English language proficiency of teachers and pupils is so low that communication is highly impaired Besides this, it is fair to add that the English- speaking world does not have a proven monopoly of technological development. It has been shown that Tanzania receives substantial technical assistance and educational grants from non-English speaking countries, this has not had much impact on the country's language policy 
At the level of the legal system however, Kiswahili has grown increasingly popular It would appear that the willingness to use Kiswahili in the superior courts is a consequence of many factors some of which have already been mentioned The most important of these includes the total localisation of the Judiciary, the Attorney General's Chambers, the Tanzania Legal Corporation and most of the Bar The heavy workload of the courts, the importance of expediting trials and the usually less than adequate ability of the court interpreters make it all the more necessary to use a language which is mutually comprehensible even if it does not happily express (with finesse) the legal concepts of the English Common Law on which the Tanzania legal system is based. Hence, although lawyers are still an economically and socially privileged class in Tanzania and their position is enhanced by their ability to speak a foreign language, they have been drawn into the use of Kiswahili because of practical needs rather than ideas associated with cultural nationalism and identity. As for the newly qualified lawyers, their apparently limited competence in the English language together with the encouragement they have found in the field, have all worked in favour of the adoption of Kiswahili in court proceedings. In sum, the argument of identity is not strong enough at this level but can serve to rationalise any difficulties which may be experienced in the use of the English language

\section{Conchusion}

This article has tried to show that there is basis for the adoption of Kiswahili as the sole language of the law in Tanzania. During the first decade and half after independence much work was done to build Kiswahili into a national language. The result is that Kiswahili has grown both in its vocabulary as well as in becoming acceptable in state administration Perhaps the most recent instance of this is the form in which the Presidential Commission on multiparty democracy, headed by Chief Justice Nyalali, has presented its report in March 1992 Two volumes the report are written in Kiswahili including its recommendations, while the third volume, which is in English, discusses the laws recommended for amendment or repeal This is also a recognition of the fact that the Commission's report would be more accessible if written in the national language. Indeed a language in which most of the people have given their views on how they would like Tanzania to be politically organised and administered

It would appear, therefore, that the future of Kiswahili as the language of the law is greatly influenced by the wider factors including state language policy. The present use of Kiswahili in the superior courts may perhaps be seen less promisingly as a temporary response to the lack of English proficiency among court clerks and in some cases, the recent law graduates But it could also be the beginning of an irreversible trend in the use of Kiswahili in the legal system Whether temporary or not, the present interest in using Kiswahili in the superior courts and its possible continuation, may well depend on the future political direction of Tanzania It will also depend upon any initiatives which will be made at the level of the legal system to support materially the use of the language and to provide a consistent material base for the use of Kiswahili in all the courts

What cannot be denied, however, is that there is at this moment some enthusiasm for the adoption of Kiswahili as an additional language of the law. There is no reason why that cannot 
be build on that by providing the needed resources as well as infrastructural support to enable law graduates to acquire the ability to use both languages wherever necessary. It is not to be expected, nor is it desirable in my view, to adopt Kiswahili to the exclusion of English in the near future. The English language will remain important as a means of communication with other common law systems and for study. There is, therefore, no conflict in maintaining both languages and using them to enhance different skills as well as to overcome particular practical difficulties

The practical as well as jurisprudential challenges of this approach may be immense but they are perhaps not unsurmountable It will be necessary first to make the important decision whether or not the legal system of Tanzania is to become properly bilingual Because if this is to be the case, it will be necessary to translate into Kiswahili important statutes and probably all future bills Whatever way one looks at this issue, it becomes evident that it is not in the best interests of Tanzania to maintain the present ambivalence in its language policy

\footnotetext{
* Faculty of Law, University of Hong Kong An earlier version of this paper was first presented at the Commonwealth Legal Education Association Conference on Emerging Educational Challenges for Law in Commonwealth Asia and Australia: The Implications for Legal Education; held on April 10th to 12th at the University of Hong Kong I would like to thank the organisers of the Conference and particularly Professor Yash P Ghai, President of CLEA, who encouraged me and made very helpful suggestions. I should also like to thank Professor Issa G Shivji, Dr. Gordon Woodman and Dr Chuma Himonga for their detailed comments and Dr C M Mukoyogo, Mr Justice Raymond Mwaikasu, Ms Anchilla Stephen and Dr Ulrike Wanitzek who provided useful sources I am also grateful to the Editors of the Journal of African Law who have granted permission to republish this article
}

\section{Bibliography}

Abdulaziz-Mkilifi, M H 1972. Triglossia and Swahili-English Bilingualism in Tanzania Language and Society Vol.1 No 2

Alam Shah 1992. "Bilingual Hazards in Legal Education and Legal Practice in Bangladesh" Paper presented at the CLEA Conference on Emerging Educational Challenges for Law in Commonwealth Asia and Australasia (Hereafter called CLEA Conference)

Batibo, H M. 1982. "Some thoughts on the Position of English Language teaching in our Primary Schools " University of Dar es Salaam (Unpublished)

Chen, A H Y 1986 "Law in a Foreign Language: The Case of Hong Kong" Hong Kong: The Challenge of Transformation, ed by Cheek-Milby \& Mushkat. Hong Kong: Centre for Asian Studie

Cowen, D V. 1980 "Language of the Law: Some reflections on the Ethics of Translation " De Rebus 145:11-16

Denny, N. 1963 "Languages in Education in Africa "Language in Africa, ed by J Spencer Cambridge: Cambridge University Press 
Dickson, L E 1991 "Legal Translation: A Literal Interpretation" Libraries and Law International No 15, ed by I C Godan and $\mathrm{H}$. Knudsen Hamburg, Agusburg

DuBow, F 1976 "Language, Law and Change: Problems in the Development of a National Legal System in Tanzania" Language and Politics, ed by W.M. O Barr and J F:O'Barrs The Hague: Mouton

Kavugha, D and D Bobb 1980 "The Use of Language in the Law Courts in Tanzania " Language in Tanzania, ed by E. Polome C.P Hill Oxford University Press, Oxford

Martin, Jones M. 1990 "Foreword to Rubagumya "Language in Education in Africa: A Tanzanian Perspective. Clevedon Philadelphia: Multilingual Matters Ltd

Mahmood, N. R. 1992. "Bilingualism in Legal Education: A Malaysian Experience " CLEA Conference

Massamba, D p 1985 "An Assessment of Development and Modernisation of the Kiswahili Language in Tanzania Paper " Presented at the Conference on Vernacular Languages for Modern Societies (Bad Homburg, Germany) ERIC Documents ED 276278

Mlama, P. and M. Matteru. 1977 Haja ya Kutumia Kiswahili Kufundishia Katika Elimu ya Juu Dar es Salaam: BAKITA

Mama, P and M Mvungi. 1982 "Language Policy \& Education Research in Tanzania: An Historical Survey." Changing Language Media, ed by Trappes -Lomax et al

Mukoyogo, M C 1991 "Can Law be Taught in Kiswahili?" Eastern Africa Law Review $18,2: 227-246$

Mukoyogo, M C nd Language and the Law in Tanzania (Unpublished mimeo )

Mvungi, M. 1974 "Language Policy in Tanzania Primary Schools with Emphasis on Implementation." M A Dissertation, University of Dar es Salaam

Mwansoko, H J M 1990 "Swahili Terminological Modernisation in the Light of the Present Language Policy in Tanzania" Language in Education in Africa: A Tanzanian Perspective, ed by C.M Rubagumya. Clevedon Philadelphia: Multilingual Matters Ltd

O Barr, W. M. 1976 "Language Use and Language Policy in Tanzania: An Overview" Language and Politics, ed by W M. O'Barr and J F. O'Barr The Hague: Mouton

Rubagumya, C. M 1986 "Language Planning in the Tanzania Education System: Problems \& Prospects. "Journal of Multilingual \& Multicultural Development 7, 4:283-300

Rubagumya, C. M ed 1990 Language in Education in Africa A Tanzanian Perspective Clevedon Philadelphia: Multilingual Matters Ltd

Rugemalira, J. M 1990. "The Communication Skills Unit and the Language Problem at the University of Dar es Salaam." Language in Education in Africa: A Tanzanian Perspective, ed by C.M. Rubagumya Clevedon Philadelphia: Multilingual Matters Ltd

Ianzania, United Republic of 1982. Ripoti Juu ya Mapendekezo ya Elimu Nchini Tanzania (The Report of the Presidential Commission on Education in Tanzania)

Tanzania, United Republic of 1980 Report of the Judicial System Review Commission DaI Es Salaam: Government Printer 
Tanzania, United Republic of 1982. Hotuba ya Wazini wa Elimu Bungeni katika kikao cha Bajeti kwa makadirio ya Fedha kwa Mwaka wa 1982/83, Dar es Salaam. (Speech of the Minister for Education to the National Assembly Budget Session of 1982/83). Dar es Salaam: Ministry of Education.

Trappes-Lomax, H R. 1990 Can a Foreign Language be a National Medium? Rubagumya C $M$ ed Language in Education in Africa: A Tanzanian Perspective Multilingual Matters Ltd Clevedon Philadelphia 94-104

Tumbo, Z. 1982. "Towards a systematic terminology development in Kiswahili." Kiswahili $49,1: 87-92$

Weston, A. B. 1965. "Law in Swahili-Problems in Developing a National Language" Swahili 35,2 .

Weston, A B 1968 Swahili Legal Terms. Dar es Salaam: Legal Research Centre \& Faculty of Law University of Dar es Salaam.

Whiteley, W. H 1969. Swahili: The Rise of a National Language London: Methuen

Wright, M 1969 . Swahili Language Policy 1890-1940." Swahili 35

Zafrullah, H M. 1992. "Law and Language in a Multiracial Society: The Switchover from English to the National Languages in Sri Lanka." CLEA Conference Paper 